\title{
Giovanni Alfonso Borelli: The Precursor of Medial Pivot Concept in Knee Biomechanics
}

\author{
Nicola Piolanti ${ }^{1}$ Simone Polloni ${ }^{1} \quad$ Enrico Bonicoli ${ }^{1}$ Michele Giuntoli ${ }^{1}$ Michelangelo Scaglione ${ }^{1}$ \\ Pier Francesco Indelli ${ }^{2}$ \\ ${ }^{1}$ Dipartimento di Ricerca Traslazionale e delle Nuove Tecnologie in \\ Medicina e Chirurgia, Università degli Studi di Pisa, Pisa, Italy \\ 2 Department of Orthopaedic Surgery, Stanford University School of \\ Medicine, Stanford University, Stanford, California, United States \\ Address for correspondence Nicola Piolanti, MD, Dipartimento di \\ Ricerca Traslazionale e delle Nuove Tecnologie in Medicina e \\ Chirurgia, Università degli Studi di Pisa, Via Paradisa 2, 56124 Pisa, \\ Italy (e-mail: nicpio@hotmail.it).
}

Joints 2018;6:167-172.

\begin{abstract}
Keywords

- knee biomechanics

- femoral rollback

- medial pivot

- total knee arthroplasty

- Giovanni Alfonso Borelli
\end{abstract}

\section{Introduction}

A new philosophy of science and medicine had spread throughout the 17 th-century Italy: contemporary scientists underscored the importance of approaching empirical experiments, mathematical concepts, and explanations only through the physical laws of nature. ${ }^{1}$

Giovanni Alfonso Borelli (1608-1679) was one of the most charismatic and brilliant scientists of his generation in Europe. ${ }^{2}$ A physicist, astronomer, and personal medical consultant to the Queen of Sweden, Borelli analyzed muscular contraction, cardiac function, blood flow, nerve transmission, pulmonary function, and many other biological issues using the modern scientific method. ${ }^{1,3}$ He extended to biology the rigorous analytic methods developed by Galileo in the field of mechanics. Historian Thomas Hall explains: "For Borelli, living bodies are machines. The whole machine is an assemblage of

received

August 13, 2018

accepted

September 9, 2018

published online

November 5, 2018 smaller components machines, and these of still smaller ones." ${ }^{4}$ He supported his theories with very beautiful, meticulous, and geometrically accurate drawings: some of them are presented in this article, directly taken from the original manuscripts jealously kept in the ancient archives of the prestigious Scuola Normale Superiore in Pisa.

\section{Early Life}

Giovanni Alfonso Borelli was born in 1608 in Naples, the firstborn son of Miguel Alonso and Laura Porella. Giovanni's father was a Spanish soldier and his family was fairly poor. In 1626, Borelli moved to Rome to study mathematics and physics under Benedetto Castelli, a student of Galileo Galilei. From 1635 to 1656 , Borelli was a lecturer in mathematics in Messina, Sicily. In 1635, the Senate of Messina offered him a coveted membership in the Accademia della Fucina, a group
Copyright $\odot 2018$ Georg Thieme Verlag License terms
KG Stuttgart · New York
DOI https://doi.org/

10.1055/s-0038-1675164. ISSN 2282-4324. 
of scientists under the protection of the Senate itself. The talented young Borelli was even designated to investigate the causes of the malignant fever that lashed a large part of Italy in 1647. He attributed the cause to an airborne infection and contested the prevailing opinion that the illness was due to excessive heat, humidity, or astrological influences. ${ }^{1}$

\section{Later life}

Around 1655, Borelli was invited to the University of Pisa by Ferdinando De' Medici Grand Duke of Tuscany, a staunch supporter of the Accademia del Cimento, a prolific Italian scientific society of that period. "By his talents and energy he made the University of Pisa famous as a school for both mathematics

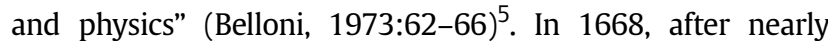
12 years in Pisa, Borelli returned to the University of Messina for a short time and then he was exiled to Rome, accused to be part of a political plot to free Sicily from Spanish rule. In 1672, he became the personal medical and scientific consultant to Christina of Sweden, during her stay in Rome after resignation.

During the last years of his life, he worked very hard on his masterpiece "De Motu Animalium," described as "a rigidly mechanical, mathematical and physical analysis of various animal functions...[which] became the bible of the iatromathematical or iatromechanical school..."6 Volume I was published in 1680, only a few months after Borelli's death, followed by Volume II, published in 1681 . Both of them were dedicated to Christina of Sweden (-Fig. 1).

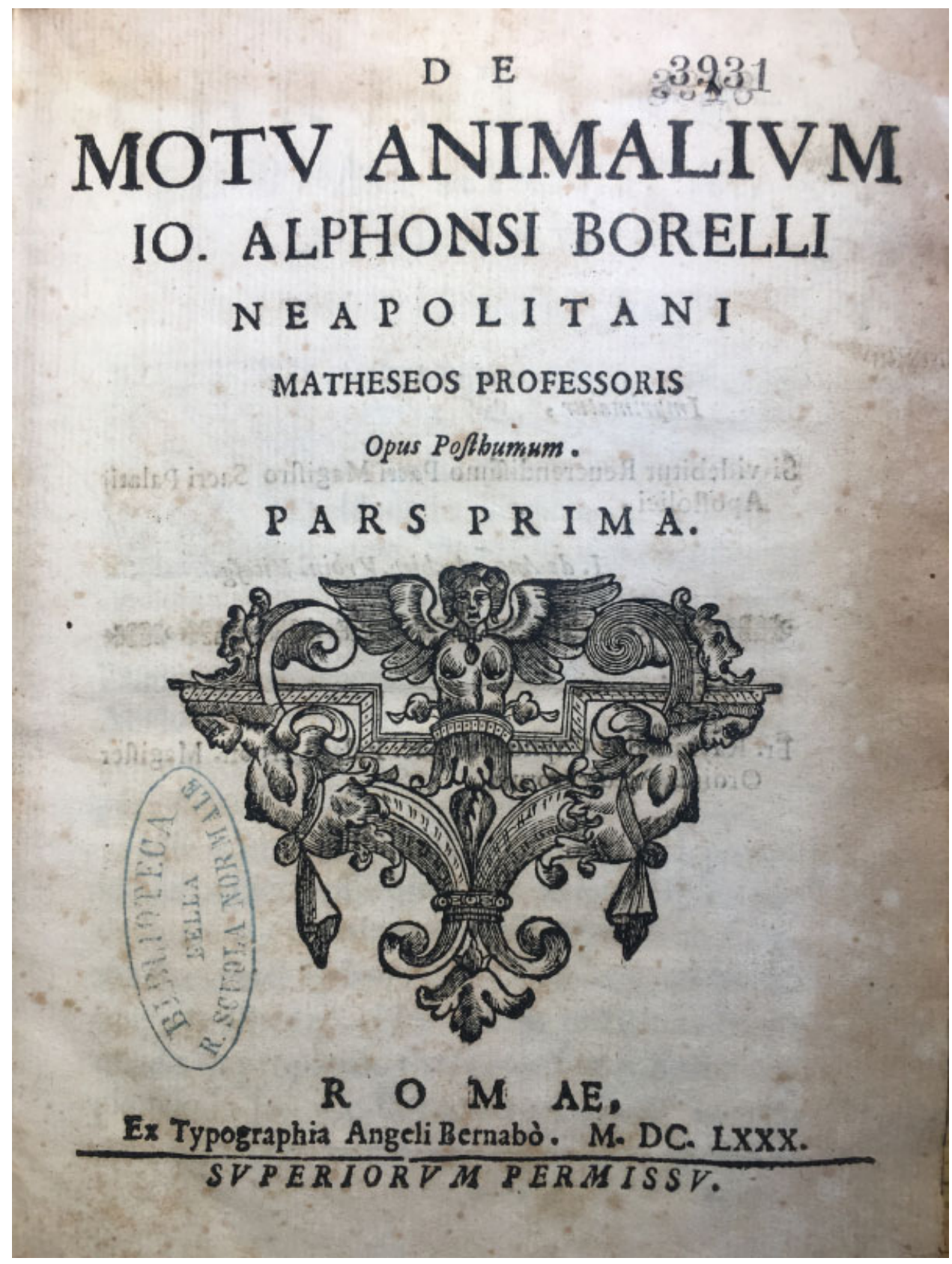

Fig. 1 Frontispiece of the original Borelli's manuscript. ${ }^{11}$ 


\section{De Motu Animalium (1680-1681)}

The first volume is concentrated on biomechanical and muscular action, both in humans and animals (e.g., during walking, running, swimming, jumping, flying). ${ }^{7,8}$ In the second volume, Borelli described the physiology of human organs such as the heart and lungs. He proposed some innovative ideas about cardiac structure and function, maintaining that the heart was structurally similar to other muscles and has the function of propelling blood into the arterial circulation. ${ }^{3} \mathrm{His}$ former pupil and collaborator Marcello Malpighi continued his work dissecting the lungs and revealing their microscopic structure consisting in branching tubes ending in sacs like grapes. ${ }^{9}$

\section{Volume I-“External Movements of Animals and Their Force"}

In the first part of his work, Borelli concentrated on movements of the "human machine" and its parts. ${ }^{10}$ Borelli analyzed structure, motion, balance, and forces concerning almost all the principal joints of human body: elbow, hip, knee, ankle, and spine. He is considered the father of spinal biomechanics thanks to his studies on vertebrae, intervertebral muscles, and discs. He deduced the exact center of gravity of the human body, confirmed only several decades later with new experiments ${ }^{1}(\boldsymbol{-}$ Fig. 2). Borelli introduced some innovative concepts about muscular structure, internal functioning, and classification. In his thinking, muscles were

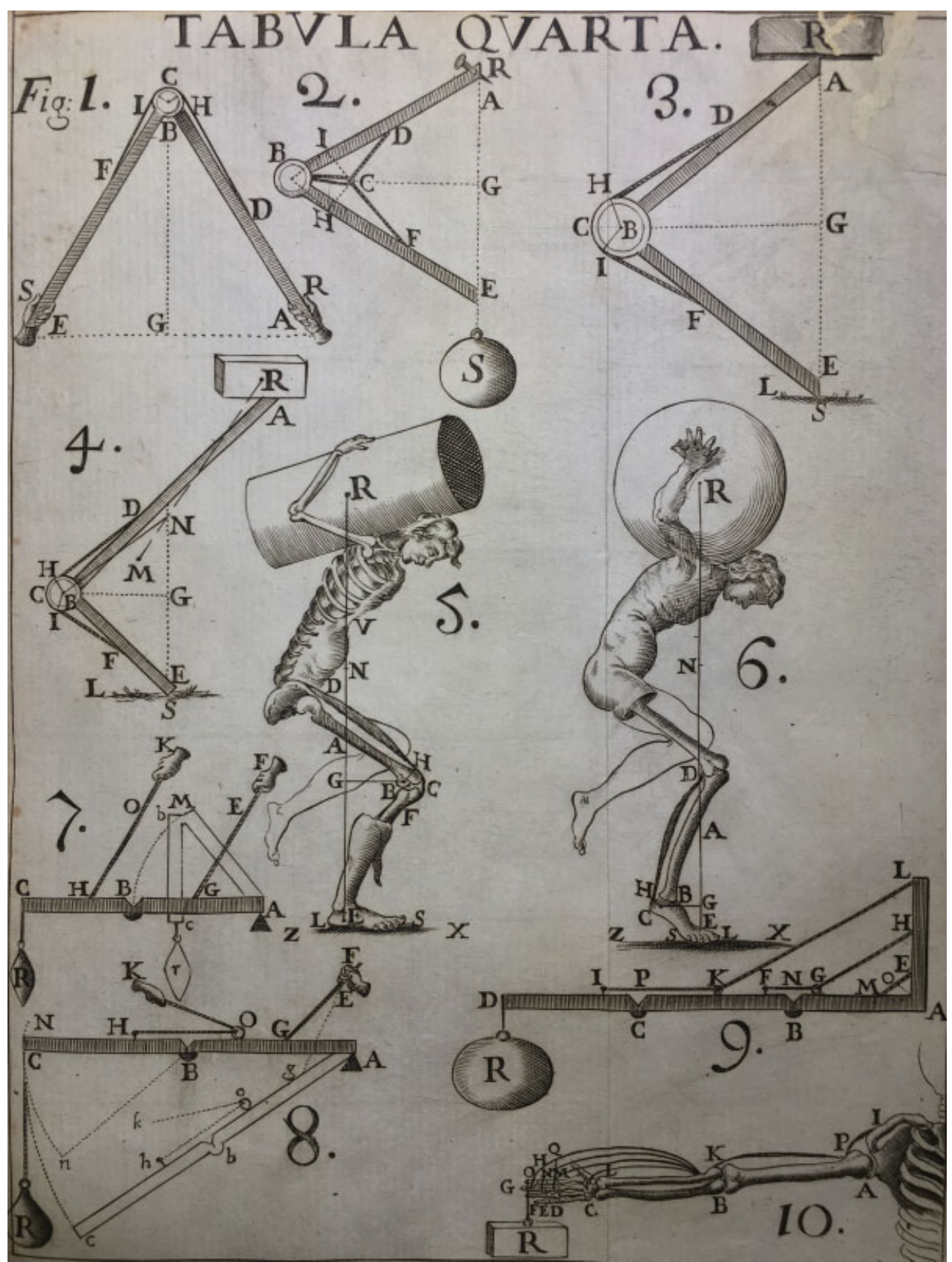

Fig. 2 Tabvla Quarta. Studies on levers and human body balance. ${ }^{11}$ 
like "working units" made up of contractile fibers assembled in small bundles, tendons, arteries, veins, and nerves ${ }^{11}$ (Propositio I). He thought that nerves secrete a thin fluid ("succus nerveus") into muscles to start the contraction process: in this way, he added a basic biochemical concept to his mechanical findings. ${ }^{12}$ He described joint motion as spherical, conical, or cylindrical around an imaginary pivot center usually situated in the epiphysis of one of the two bones involved ${ }^{11}$ (Propositio IV). Making an extensive use of levers' principles, Borelli described the contraction forces of muscles around joints with physical demonstrations. He sustained the necessity of force application nearby the pivot center of the joints, especially for encumbrance issues. In this way, the resultant force applied by muscles was lowered, but he appreciated that nature had made up this limitation: moving the tendons' insertion on some bone tuberosity or inserting some sesamoid bone (e.g., the patella in the knee joint), lever arms could be increased and finally muscle force improved $^{11}$ (Propositio XX).

\section{Volume I-Chapters IX-XI, Studies on the Knee}

Borelli accurately studied the anatomy and biomechanics of the knee joint ${ }^{11}$ (-Fig. 3). He described the rotational movement of the tibial plate on the epiphyseal end of the femur. He illustrated the flexor muscles tendons as reins for horses, attaching on proximal tibial and peroneal end. Borelli examined the working principles of the knee joint as a machine composed of two arms (the femur and tibia/fibula), hinged

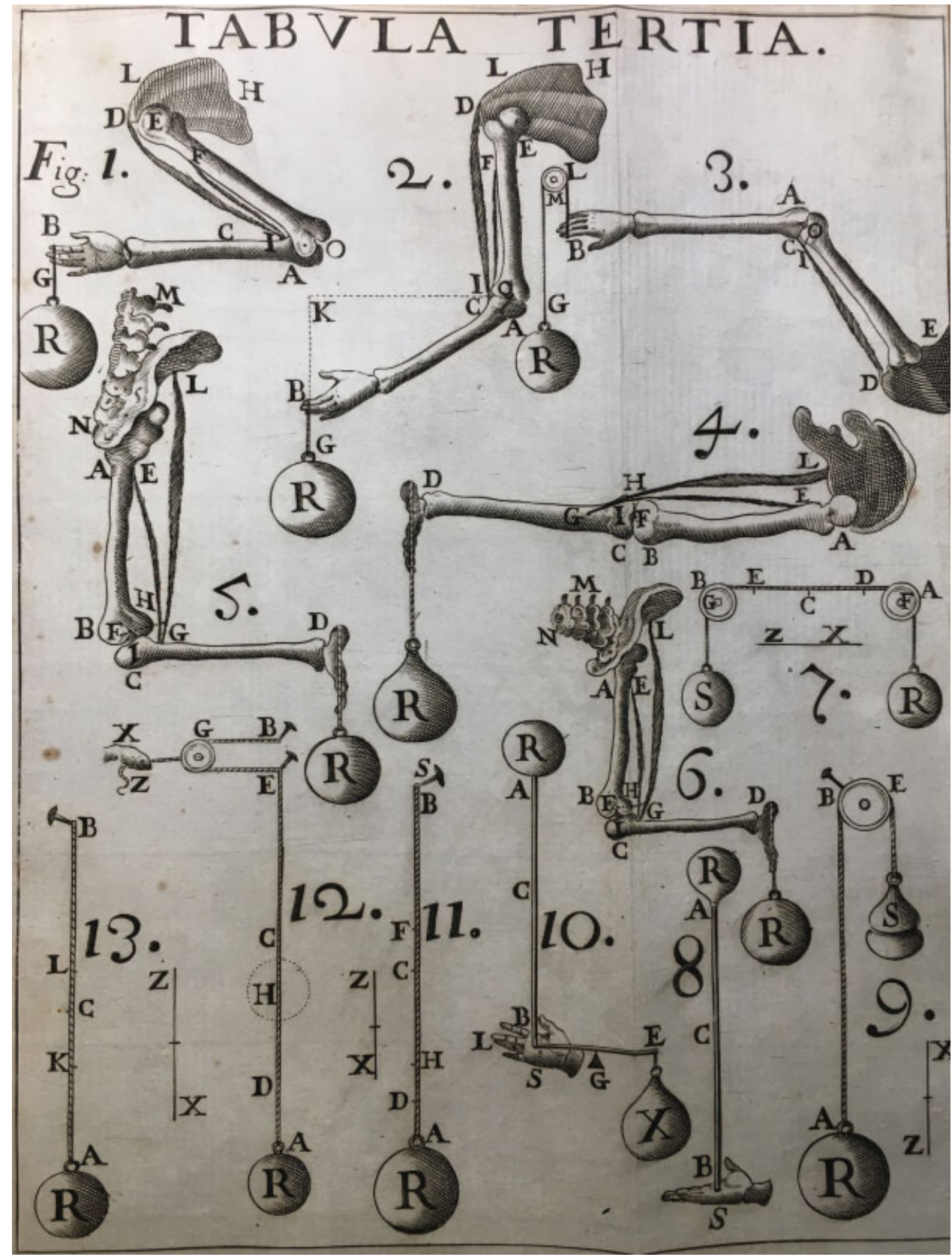

Fig. 3 Tabvla Tertia. Studies on forces around joints in the upper and lower limbs. ${ }^{11}$ 
each other at the level of the knee and sustaining a load at the heel. The insertion of extensor and flexor muscles is situated at the proximal end of the tibia, creating a disadvantageous lever ${ }^{11}$ (Propositio XXVII). Borelli observed the lack of congruence of the femoral and tibial articular surfaces. He postulated the role of fibrocartilage structures to increase this congruence, acting as a cushion interposed between the two bones. Medial and lateral meniscus moved backward during knee flexion. Furthermore, Borelli is probably one of the first scientists to introduce the concept of multiplanar movement of knee joint components. In addition to flexion and extension, however macroscopically more visible, he sustained that femoral condyles shift backward during flexion, allowing a wider range of movement ${ }^{11}$ (Chapter IX, p. 51). This concept is nowadays known as "femoral rollback," and it is a cornerstone of the complex biomechanics of the knee. ${ }^{13,14}$ Reading closely the first part of Chapter IX (p. 51), we can find this words: “...in flexione tibię...tendo GIH contingit summitatem posteriorem lateralem infimi capitis fæmoris..." 11 (translating from ancient Latin: during the flexion of the tibia...the GIH tendon (i.e., hamstring tendons) comes into contact with the upper part of the posterior and lateral distal end of the femur). This means that, when the knee flexes, the lateral condyle moves backward more than the medial condyle. This mechanism has become part of the modern thinking only in recent times as "medial pivoting": during flexion of the knee, the tibia tends to intrarotate pivoting on the medial femoral condyle. ${ }^{15,16}$

\section{Borelli's Unrecognized Contribution in Total Knee Arthroplasty}

During the last quarter of the 20th century, knowledge about knee prosthesis design has grown exponentially. The goal was to reproduce the complex normal knee while functioning with an artificial device. For this reason, a lot of energy has been invested in studying the normal knee biomechanics. At the beginning of the century, on the basis of radiographic studies, Zuppinger was the first to officially propose the concept of "femoral rollback," a hypothesis initially rejected by his contemporaries. During the second half of 1900, the idea of a fourbar link mechanism composed of the two cruciate ligaments, the femur and the tibia, producing the movements of flexion, femoral rollback, and tibia internal rotation was developed and became popular especially thanks to Kapandji's studies. ${ }^{17,18}$

Many recent studies confirmed Borelli's pioneer hypotheses. In vitro studies on cadaver showed approximately 11 degrees of tibial internal rotation during passive knee flexion. ${ }^{15}$ In vivo fluoroscopic analyses demonstrated a major rollback of the lateral femoral condyle compared with the medial one ( 13 vs. $3 \mathrm{~mm}) .{ }^{19}$ Using modern imaging technology, the medial pivoting phenomenon was accurately described too. Multiplanar three-dimensional computed tomography reconstructions showed important differences in condyles rollback during flexion (21 vs. $2 \mathrm{~mm}$ of backward translation of the lateral condyle compared with the medial one). ${ }^{16}$ Dynamic magnetic resonance analysis confirmed that finding, showing approximately 15 degrees of tibia internal rotation ${ }^{20}$ during knee flexion.
Basing on these knowledge, the conceptualization of a new medial pivot prosthesis design took place only in 1994 with the Freeman-Samuelson model. ${ }^{21,22}$ A medial pivot knee system was developed to address residual pain and the patient's desire for fully restored anatomical function after total knee replacement. ${ }^{23}$ An increased stability of the implants was observed throughout the entire range of motion $^{24}$ guaranteed by a "ball-and-socket" articulation of the medial tibiofemoral compartment, and a reduction of polyethylene wear with no additional fixation problems. ${ }^{21}$ Many studies show an excellent long-term survival rate. Fitch et al estimated a pooled survivorship of $97.6 \%$ at 8 years' follow-up of a medial pivot prosthesis model implanted in 1,146 knees. $^{25}$ Other studies reported even better results with longer follow-up: Macheras et al observed a survivorship rate of $98.8 \%$ at 17 years ${ }^{26}$; Nakamura et al demonstrated a survival rate of $99.1 \%$ at 10 years. ${ }^{27}$ Patients' satisfaction was reported to be excellent too, ${ }^{28}$ even better if compared with conventional prosthesis design. ${ }^{29}$ Pritchett interviewed 344 patients with a different prosthesis model implanted on each knee and reported a preference of medial pivot versus conventional posterior cruciate-retaining devices in $79 \%$ of the patients. ${ }^{30}$

Ultimately, the concepts of femoral rollback and medial pivoting are considered achievements of the last decades and have led to revolutionary prosthesis designs only recently. In reality, as far as 1680 , Borelli reported these findings, rejected by his contemporaries and forgotten until the 20th century.

\section{Conclusion}

Giovanni Alfonso Borelli has contributed to evolve science and medicine of the 17th century from magic and astrological beliefs to well-founded principles of mathematics and physics. ${ }^{1}$ He tried to explain the functioning of many human organs with solid demonstrations and experiments, starting with the musculoskeletal system and ending with the respiratory and cardiovascular systems. De Motu Animalium (1680-1681) is considered his masterpiece and seemingly constitutes the very first treatise of biomechanics. ${ }^{31}$ Some innovative concepts introduced by him still apply today. In particular, he was the first scientist to realize the very modern concepts of "femoral rollback" and "medial pivoting," well described only during the 20th century and nowadays has become cornerstones of knee biomechanics and knee prosthesis design. In recognition of his heritage, the American Society of Biomechanics, founded in 1977 and having the mission to encourage the spread of biomechanical theories in different disciplines, every year bestows the most deserving scientific exponent in the field with the "Borelli Award." 32

Conflict of Interest

None declared.

\section{References}

1 Provencher MT, Abdu WA. Giovanni Alfonso Borelli: "Father of spinal biomechanics.”. Spine 2000;25(01):131-136 
2 Borelli GA. (translated by Paul Maquet). Borelli's On the Movement of Animals - On the Force of Percussion. Studies in history and philosophy of science. Springer International. 2015; Vol. 37

3 Fye WB. Giovanni Alfonso Borelli. Clin Cardiol 1996;19(07): 599-600

4 Hall TS. Ideas of Life and Matter: Studies in the History of General Physiology, 600BC-1900AD. Chicago: University of Chicago Press; 1969:347-348

5 Belloni L. Marcello Malpighi. In: Gillispie CC, ed. Dictionary of Scientific Biography. Vol. 9. New York: Charles Scribner's Sons; 1973:62-66

6 Adelmann HB. Marcello Malpighi and the Evolution of Embryology. Vol. 1. Ithaca: Cornell University Press; 1966:192

7 Bendiner E. Marcello Malpighi: a life of passionate exploration. Hosp Pract 1980;15(07):109-136

8 Baker R. The history of gait analysis before the advent of modern computers. Gait Posture 2007;26(03):331-342

9 Breimer L, Sourander P. Alphonso Borelli and Christina. The father of kinesiology and the Queen of Sweden. Clio Med 1983;18(1-4):155-165

10 Borelli GA. De motu animalium (a cura di O. Cappellini, traduzione M.T. Bruscolini). Argalia Editore Urbino; 1970. Vol. I

11 Borelli JA. De motu animalium pars prima. Opus posthumum. Romae: Ex Typographia Angeli Bernabò; 1680; Fondo antico della Biblioteca della Scuola Normale Superiore, Pisa

12 Conforti M. Succcus nerveus and succus seminalis in Borelli's living machine [in Italian]. Med Secoli 2001;13(03):577-595

13 Freeman MA, Pinskerova V. The movement of the normal tibiofemoral joint. J Biomech 2005;38(02):197-208

14 Pinskerova V, Johal P, Nakagawa S, et al. Does the femur roll-back with flexion? J Bone Joint Surg Br 2004;86(06):925-931

15 Li G, Zayontz S, DeFrate LE, Most E, Suggs JF, Rubash HE. Kinematics of the knee at high flexion angles: an in vitro investigation. J Orthop Res 2004;22(01):90-95

16 Dennis DA, Mahfouz MR, Komistek RD, Hoff W. In vivo determination of normal and anterior cruciate ligament-deficient knee kinematics. J Biomech 2005;38(02):241-253

17 Scott G, Imam MA, Eifert A, et al. Can a total knee arthroplasty be both rotationally unconstrained and anteroposteriorly stabilised? A pulsed fluoroscopic investigation. Bone Joint Res 2016;5 (03):80-86
18 O'Connor JJ, Shercliff TL, Biden E, Goodfellow JW. The geometry of the knee in the sagittal plane. Proc Inst Mech Eng H 1989;203(04): 223-233

19 Komistek RD, Dennis DA, Mahfouz M. In vivo fluoroscopic analysis of the normal human knee. Clin Orthop Relat Res 2003;(410):69-81

20 Hill PF, Vedi V, Williams A, Iwaki H, Pinskerova V, Freeman MA. Tibiofemoral movement 2: the loaded and unloaded living knee studied by MRI. J Bone Joint Surg Br 2000;82(08):1196-1198

21 Mannan K, Scott G. The Medial Rotation total knee replacement: a clinical and radiological review at a mean follow-up of six years. J Bone Joint Surg Br 2009;91(06):750-756

22 Benjamin B, Pietrzak JRT, Tahmassebi J, Haddad FS. A functional comparison of medial pivot and condylar knee designs based on patient outcomes and parameters of gait. Bone Joint J 2018;100-B (1, Supple A):76-82

23 Aumiller WD, Dollahite HA. Advances in total knee arthroplasty. JAAPA 2016;29(03):27-31

24 Blaha JD. The rationale for a total knee implant that confers anteroposterior stability throughout range of motion. J Arthroplasty 2004;19(04, Suppl 1):22-26

25 Fitch DA, Sedacki K, Yang Y. Mid- to long-term outcomes of a medialpivot system for primary total knee replacement: a systematic review and meta-analysis. Bone Joint Res 2014;3(10):297-304

26 Macheras GA, Galanakos SP, Lepetsos P, Anastasopoulos PP, Papadakis SA. A long term clinical outcome of the Medial Pivot Knee Arthroplasty System. Knee 2017;24(02):447-453

27 Nakamura S, Minoda Y, Nakagawa S, et al. Clinical results of alumina medial pivot total knee arthroplasty at a minimum follow-up of 10years. Knee 2017;24(02):434-438

28 Karachalios T, Varitimidis S, Bargiotas K, Hantes M, Roidis N, Malizos KN. An 11- to 15-year clinical outcome study of the Advance Medial Pivot total knee arthroplasty: pivot knee arthroplasty. Bone Joint J 2016;98-B(08):1050-1055

29 Hossain F, Patel S, Rhee SJ, Haddad FS. Knee arthroplasty with a medially conforming ball-and-socket tibiofemoral articulation provides better function. Clin Orthop Relat Res 2011;469(01):55-63

30 Pritchett JW. Patient preferences in knee prostheses. J Bone Joint Surg Br 2004;86(07):979-982

31 Maquet P. Borelli: De Motu Animalium. A first treatise on biomechanics [in French]. Acta Orthop Belg 1989;55(04):541-546

32 Pope MH. Giovanni Alfonso Borelli-the father of biomechanics. Spine 2005;30(20):2350-2355 